THERAPEUTIC TARGETS

\section{From microarray to mechanism}

Why do patients with diffuse large B-cell lymphoma (DLBCL) - the most common form of nonHodgkin's lymphoma - have such a variable response to chemotherapy? Eric Davis and colleagues now provide a rational basis for developing new types of therapies for the poor responders.

Microarray studies indicate that there are two types of DLBCL, one resembling resting, germinal-centre B cells (GC-DLBCL), the other, which responds poorly to standard chemotherapy, with characteristics of activated $B$ cells (ABC-DLBCL). Analysis of these published results revealed that several genes in the NF- $\kappa B$ pathway are highly expressed in ABC-DLBCL, but not in GC-DLBCL. The same was true of cell lines derived from the two DLBCL types, and band-shift assays showed that high levels of NF- $\kappa B$ capable of binding its target sequences were present in ABC-DLBCL lines, but not in GC-DLBCL lines.

$\mathrm{NF}-\mathrm{KB}$ is activated by degradation of its inhibitory subunit, IкB. The signal that sends I $\mathrm{B}$ for destruction is phosphorylation by ІкB kinase (IKK). Is this pathway operative in ABC-DLBCL? In vitro kinase asays revealed that IKK from $A B C$ DLBCL cell lines, but not from GCDLBCL cell lines, was constitutively active and, when protein synthesis
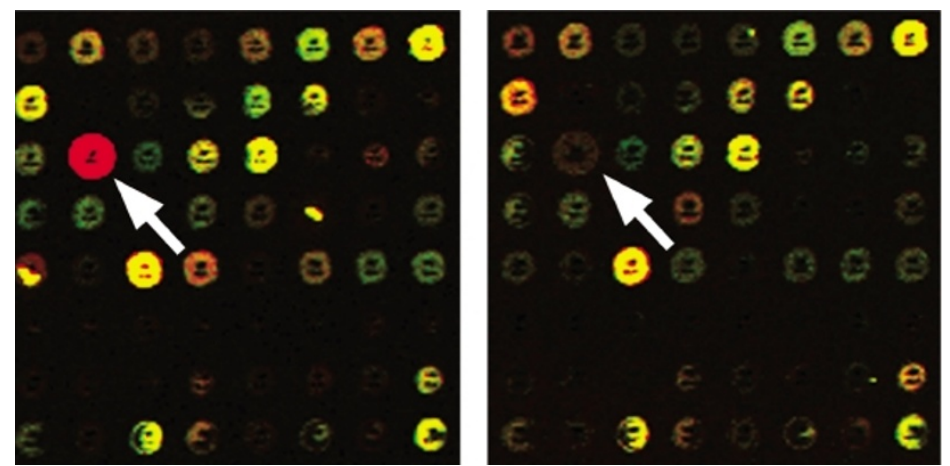

Microarray images from patients with germinal-centre B-like diffuse large B-cell lymphoma (left) versus activated B-like diffuse large B-cell lymphoma. Courtesy of Louis Staudt, National Cancer Institute, Bethesda, Maryland, USA.

was blocked, levels of IкB in ABCDLBCL cells plummeted, whereas $\mathrm{I} \kappa \mathrm{B}$ in GC-DLBCL cells was much more stable. So, NF-KB seems to be activated in ABC-DLBCL cells through the classical IKK pathway.

The authors then tried to block $\mathrm{NF}-\mathrm{KB}$ signalling by introducing a 'super-repressor' mutant of IKB that cannot be phosphorylated by IKK. ABC-DLBCL cells but had no effect on the survival of GC-DLBCL cells. So, ABC-DLBCL cells seem to rely on their constitutively active NF- $\mathrm{\kappa B}$ signalling pathway for survival. Likewise, a dominant-negative mutant of IKK $\beta$ was also selectively toxic to ABC-DLBCL cells.

This mechanistic difference between the two types of DLBCL not only indicates why ABC-DLBCL might be more resistant to chemotherapy than the GC type, but also suggests a means of tackling that resistance. Drugs that block the NF- $\kappa \mathrm{B}$ pathway are already in clinical trials, so it should not be long before these observations are put to the most important test of all - in DLBCL patients.

Cath Brooksbank

(D) References and links ORIGiNAL RESEARCH PAPER Davis, R. E. et al. Constitutive NF-kB activity is required for survival of activated B-like diffuse large B-cell lymphoma cells. J. Exp. Med. 194, 1861-1874 (2001) FURTHER READING Alizadeh, A. A. et al. Distinct types of diffuse large B-cell lymphoma identified by gene expression profiling. Nature $\mathbf{4 0 3}$, 503-511 (2000) The super-repressor was toxic to of 120 patients who received surgery followed by interferon- $\alpha$ $2 \mathrm{~b}$ was 11.1 months, whereas the average survival time for 121 patients who received interferon- $\alpha-2 b$ therapy alone was only 8.1 months.

Although the statistical significance of this study is debatable, the results do support those of a recent, smaller trial. The authors conclude that the combined treatment should be considered the standard of care in future Phase III trials.

ORIGINAL RESEARCH PAPER Flanagan, R. C. et al. Nephrectomy followed by interferon $\alpha-2 b$ compared with interferon $\alpha 2 b$ alone for metastatic renal-cell cancer. N. Engl. J. Med. $345,1655-1659$ (2001)

FURTHER READING Tannock, I. F. Removing the primary tumor after the cancer has spread. N. Engl. J. Med. 345, 1699-1700 (2001) | Mickisch, G. H. J. et al. Radical nephrectomy plus interferon- $\alpha$-based immunotherapy compared with interferon $\alpha$ alone in metastatic renal-cell carcinoma: a randomised trial. Lancet 358, 966-970 (2001) 